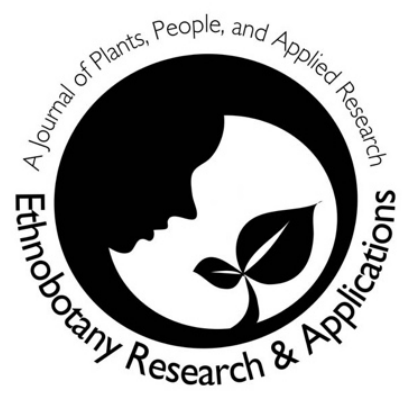

\title{
Book review of Economically Important Plants of District Rajouri, J \& K, Western Himalaya
}

\author{
Zubair A. Malik
}

Correspondence

Zubair A. Malik1, 2

${ }^{1}$ Department of Botany and Microbiology, HNB Garhwal University, Srinagar Garhwal Uttarakhand (India)-246174

2 Presently at Department of Biology, Govt. HSS Harduturoo Anantnag (J\&K)- 192201

*Corresponding Author: malikmzubair081@gmail.com

Ethnobotany Research \& Applications 22:09 (2021)

\section{Book Review}

\begin{abstract}
Economically Important Plants of District Rajouri, J \& K, Western Himalaya. Shreekar Pant, Zishan Ahmad Wani, Adil Farooq and Virbala Sharma. Indu Book Services Private Limited, New Delhi 2021. xii + 258 pp. Price: ₹ 2995, ISBN: 978-93-86754-75-2.

The book under review (Economically Important Plants of District Rajouri, J \& K, Western Himalaya-Volume I) is an attempt of researchers (Shreekar Pant, Zishan Ahmad Wani, Adil Farooq and Virbala Sharma) of Baba Ghulam Shah Badshah University, Rajouri to develop a field guide with all necessary details like local name, nativity, parts use, ethnomedicinal uses, phytochemicals, pharmacological activities, and other uses along with taxonomic characters and coloured photographs. The pictorial guide provides first-hand information on diversity, utilization patterns and traditional uses (along with some published pharmacological and phytochemical information) of 285 wild and cultivated economically important plant species of District Rajouri. It is expected to be highly useful to its wide audience of plant taxonomists, conservationists, foresters, researchers, students, and nature lovers.
\end{abstract}

With about 270 pages, published by Indu Book Services Pvt. Ltd., the book is especially designed for the students and researchers of Himalayan region. In the preface, Dr. A. A. Mao, Director, Botanical Survey of India, appreciates the tireless efforts of the authors for undertaking a colossal task of identification, cataloguing, and organizing multifaceted information on different aspects of economically important plants of District Rajouri.

The book is divided into 2 major sections. Section 1 deals with the Assessment (and conservation \& management) of economically important plants of Rajouri. The plants described in this section belong to 3 plant groups i.e. Pteridophytes, Gymnosperms and Angiosperms. However, the information about other groups (algae, bryophytes, lichens) is missing. The distribution of described plants as given on P 2 is: trees (88); shrubs (51); herbs (138); gymnosperms (11) and pteridophytes (08). The sum of all these plant species is 296 and not 285. The number of tree species is wrongly shown as 88 , actual number of tree species described is only 77 and not 88 .

On the first page of Section 1, the details of plant diversity of J\&K are given but the number of species (of different plant groups) presented here is much less and contradicting to those presented in the recently published book "Biodiversity of the Himalaya: Jammu and Kashmir State" of Dar and Khurroo (2020). For example, the number of species presented here includes 168 pteridophytes, 19 gymnosperms and 4439 angiosperms while the figures presented in Dar and Khuroo (2020) include 200 pteridophytes, 41 gymnosperms and 5056 taxa of angiosperms including 4778 species and 278 subspecies/varieties. This book (Biodiversity of the Himalaya: Jammu and Kashmir 
State) of Dar and Khurroo (2020) is considered to be an authentic source of knowledge on the biodiversity of J\&K that contains a comprehensive, up-to-date and consolidated synthesis of all known biodiversity of J\&K (Malik, 2020). The book (Dar and Khurroo, 2020) is missing in the bibliography and hence it is clear that authors have not consulted this book before giving the details of different plant groups of J\&K. Half of the references cited here ( $P$ 1) are outdated belonging of eighties and nineties.

The authors should have included a separate section "The Study Region-Rajourl" in the beginning (before the listing of plant species) wherein all the details of Rajouri (like location, geology, geography, climate, and vegetation) can be presented for the readers not familiar with this part of Himalaya.

The plant species described (under different plant groups) are arranged in an alphabetic order. For each plant species, the information on various aspects is provided including botanical name, family, local name, nativity, taxonomic description, ethnomedicinal utility, parts used, phytochemistry, pharmacological activities and other uses. What is missing here includes synonyms, vernacular names in at least other regions of J\&K (Kashmir \& Ladakh), ecology, phenology (especially flowering \& fruiting time) and geographical distribution of plant species. No doubt, the book is about the plants of Rajouri, but the including the ethnomedicinal utility from other parts of country (and/or world) would make it much interesting and worth reading. Another issue that can be easily noticed is that the information pertaining to ethnomedicinal uses, phytochemistry and pharmacological activities of plants are not properly cited.

Trade values for some of the economically important plants known from local as well as different markets of the country are given and to ensure the long-term conservation of economically important plants and availability of their products in district Rajouri, few sound recommendations are given by the authors at the end of the first section.

As far as the $2^{\text {nd }}$ section (Comparative Analysis of World's Online Data Bases) of this book is concerned, I think it is not absolutely necessary. According to the authors, "With the advent of modernization many scientific changes have occurred in plant classification/nomenclature". Online Data Bases like The Plant List (TPL) and Plants of the World Online (POWO) are used for comparing the scientific names of plants. But only a few species have very little difference in their names or authorities, the rest is same in both the compared data bases. Out of the total 285 species described in this book, only about 20 species (e.g., Thuja orientalis, Acacia catechu, Callistemon citrinus, Litsea chinensis etc) showed differences in their names and/or authorities in TPL and POWO. It would have been much better, if only these species were mentioned in this section; and the best if these deviations were mentioned along with the plant description itself while describing them in section 1 . If the authors do so in next edition/volume, at least 14 pages will be saved. Moreover, spelling of some species (Cheilocostus speciosus, Bombax ceiba) is wrongly presented (Cheilicostus speciosus ( $\mathrm{P}$ 185), Bombax cebia (P178)). Spelling of Bombax ceiba is wrongly presented throughout the book. Nomenclature details of Prinsepia utilis (as per TPL and POWO) are missing (P182).

Next section is 'Colour Section' (P 191-239) that contains maps of Rajouri and coloured photographs of the plant species described in this book. Normally, figures are (and should be) placed next to the relevant text (or just after their first mention) in the book/article. But in the book under review, the case is different. Study area (Rajouri) is described at P 2 while its maps are placed in 'Colour Section' at the end (P 191). Plants are described at P 7-175, while their photographs are kept at the end (P 192-240). This could frustrate and irritate the readers.

Only one photograph is provided for each plant species. The authors should provide at least 2-3 high quality photographs (for each plant) showing the habit (life form) of adult plant and close-ups of flowers, inflorescence, fruits, or any other typical taxonomic characters that could help in identification. On P 201, a photograph of seedling/sapling of Grewia oppositifolia is shown. The readers (especially those who are not familiar with the vegetation of Himalayan region) can never imagine how an adult $G$. oppositifolia will look like. So different highquality photographs including some close-ups (placed near or next to the plant description) are necessary especially for pictorial guides. Some of the photographs, for example, those of Grevillea robusta, G. oppositifolia, Leucaena leucocephala, Buddleja asiatica, Amaranthus caudatus, Malvastrum coromandelianum, Ocimum basilicum etc. are not of good quality.

The price of this book is extremely high (₹2995) for the personal collection, but libraries of colleges, universities and research organizations can make it available to the students, researchers, and general public. 
Despite the above-mentioned shortcomings (which can be improved in next editions/volumes), the book provides a baseline information/data for further studies on the topic of economically important plants of Rajouri or whole J\&K. Including the index of plant species at the end of book is appreciable. The plant species are arranged in an alphabetical order that will help the reader to locate a particular plant species immediately. The recommendations contained in this book, if implemented properly and followed sincerely, will surely help in the conservation and management of economically important plants in the whole Himalayan region.

\section{Literature Cited}

Dar GH, Khuroo AA. 2020. Biodiversity of the Himalaya: Jammu and Kashmir State (Vol. 18). Springer Nature, Singapore. doi: 10.1007/978-981-32-9174-4

Malik ZA. 2020. Book review of Biodiversity of the Himalaya: Jammu and Kashmir State. Biodiversity and Conservation 29:3860-3861. doi: 10.1007/s10531-020-02054-x 